\title{
Activity of Oxygen in Liquid $\mathrm{Cu}-\mathrm{Bi}$ Alloys*
}

\author{
By Shinya Otsuka**†, Hirotaka Hanaoka*** and Zensaku Kozuka**
}

\begin{abstract}
Modified coulometric titrations on the electrochemical cell: $\underline{\mathrm{O}}$ in liquid $\mathrm{Cu}-\mathrm{Bi}$ alloys $/ \mathrm{ZrO}_{2}$ $(+\mathrm{CaO}) /$ Air, $\mathrm{Pt}$, were performed to determine the activity coefficients of oxygen, $\gamma_{\mathbf{o}}$, in liquid $\mathrm{Cu}-\mathrm{Bi}$ alloys at $1373 \mathrm{~K}$ as a function of alloy composition.

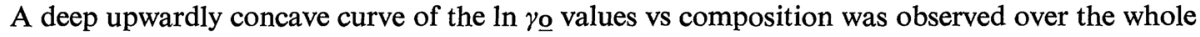
composition range of alloys, as predicted by several solution models. The measured data itself, however, are considerably lower than the calculated values, especially those according to the regular solution model. The interaction parameter of bismuth on oxygen is evaluated from the data for the dilute alloy of bismuth to be -12.0 at $1373 \mathrm{~K}$.
\end{abstract}

(Received July 2, 1982)

\section{Introduction}

There are two important contributions to the activity coefficients of oxygen, $\gamma_{\underline{\underline{O}}}$ in liquid binary A-B alloys. The first effect, identified by Alcock et al. ${ }^{(1)(2)}$ and Wagner ${ }^{(3)}$, may be visualized by considering the difference between $\ln \gamma_{\underline{Q}(\mathrm{~A})}$ and $\ln \gamma_{\underline{Q}(\mathrm{~B})}$, where $\gamma_{\underline{Q}(\mathrm{~A})}$ and $\gamma_{\underline{Q}(\mathrm{~B})}$ are the activity coefficients of the infinitely dilute solution of oxygen in pure $A$ and $B$, respectively ${ }^{(4)}$. As the value of $\left|\ln \gamma_{\underline{O}(A)}-\ln \gamma_{\underline{O}(B)}\right|$ increases, the average composition of the metal atoms bonded to oxygen begins to deviate significantly from the bulk composition of alloy. As a result, the plots of $\ln \gamma_{\mathrm{o}}$ vs alloy composition show considerable negative deviations from the additive equation, $\mathrm{N}_{\mathrm{A}} \ln \gamma_{\mathbf{O}(\mathrm{A})}+$ $N_{B} \ln \gamma_{O(B)}$ with $N_{A}$ and $N_{B}$ being the mole fractions of $A$ and $B$ in the A-B alloys.

When $\ln \gamma_{\underline{O}(A)}$ in nearly equal to $\ln \gamma_{\underline{O}(B)}$, this effect on the compositional variation of $\ln \gamma_{0}$ obviously disappears, and therefore, the second effect due to the solution behavior of A-B alloys may become predominant. Thus,

* This paper was presented at the Annual Meeting of the Japan Inst. Metals in Tokyo in Apr. 1981.

** Department of Metallurgical Engineering, Faculty of Engineering, Osaka University, Suita, Osaka 565, Japan.

** $\uparrow$ Present Address: Department of Metallurgical and Mineral Engineering, University of Wisconsion, Madison, Wisconsin 53706, U.S.A.

*** Graduate School, Osaka University, Suita, Osaka. Present address: Kobe Steel Ltd., Kobe 651, Japan. much attention has been paid to the Bi-Tl-O and $\mathrm{Cu}-\mathrm{Bi}-\mathrm{O}$ systems satisfying the condition of $\ln \gamma_{\underline{O}(A)} \approx \ln \gamma_{\underline{O}(B)}$. Positive deviations of $\ln$ $\gamma_{\mathrm{O}}$ from the additive equation have recently been reported over the entire composition range of $\mathrm{Bi}-\mathrm{Tl}$ alloys ${ }^{(5)}$, which are formed exothermally from the pure components ${ }^{(6)}$. However, reliable experimental data are scarce for the oxygen behavior in liquid $\mathrm{Cu}-\mathrm{Bi}$ alloys, which are formed endothermally from the pure components. In the present investigation, the activity coefficients of oxygen, $\gamma_{0}$, in liquid $\mathrm{Cu}-\mathrm{Bi}$ alloys at $1373 \mathrm{~K}$ are measured by using the modified coulometric titration method described previously ${ }^{(5)(7)-(11)}$. The results are compared and discussed with those for the $\mathrm{Bi}-$ Tl-O system.

\section{Experimental}

Details for theoretical basis for the coulometric technique have been presented in earlier publications $^{(5)(7)-(11)}$. The apparatus and experimental procedure used in this study are similar to those in a previous study for pure copper $^{(9)}$. Some are reproduced here for convenience.

\section{Materials}

Copper used in this study was of 99.998 mass \% purity with the following impurities: $\mathrm{Ag} 4 \mathrm{ppm}$, Fe $3 \mathrm{ppm}$, Ni $1 \mathrm{ppm}, \mathrm{Pb} 2 \mathrm{ppm}$, Sn 1 ppm, Zn 2 ppm, S 4 ppm, and $\mathrm{Au}, \mathrm{Al}, \mathrm{As}$, $\mathrm{Bi}, \mathrm{Cd}, \mathrm{Sb}, \mathrm{Se}, \mathrm{Si}, \mathrm{Te} 0 \mathrm{ppm}$. Bismuth used in this study was of 99.999 mass.\% purity. These 
metals were loaded into a solid electrolyte tube in quantity corresponding to $60-63 \mathrm{~mm}$ height in the liquid state of alloys. The $\mathrm{ZrO}_{2}$ $(+5$ mass $\% \mathrm{CaO})$ solid electrolyte tube closed at one end was obtained from Nippon Kagaku Togyo Co., Ltd. in the form of $8 \mathrm{~mm}$ o.d., $5 \mathrm{~mm}$ i.d. and $300 \mathrm{~mm}$ length. Platinum paste was painted on the electrolyte over a length of $65 \mathrm{~mm}$ from its bottom. Rhenium wires, used as lead wires for the melts, were attached to Kanthal wires in a uniform temperature zone. Measured emf's were corrected for the thermoelectric emf's between the platinum and Kanthal wires, $(15.0 \mathrm{mV}$ at $1373 \mathrm{~K})$. All emf's presented in this paper are corrected values.

\section{Experimental principle and procedure}

An electrochemical cell: $\underline{\mathrm{O}}$ in liquid $\mathrm{Cu}-\mathrm{Bi}$ alloys $/ \mathrm{ZrO}_{2}(+\mathrm{CaO}) / \mathrm{Air}, \mathrm{Pt}$, involving a solid electrolyte tube was constructed as shown in Fig. 1. After the stabilized zirconia tube was evacuated and purified argon gas introduced into the tube, the furnace was heated to $1373 \mathrm{~K}$. The liquid $\mathrm{Cu}-\mathrm{Bi}$ alloy was first stirred for about $1.2 \mathrm{ks}$ in order to establish a uniform alloy composition throughout the melt. Second,

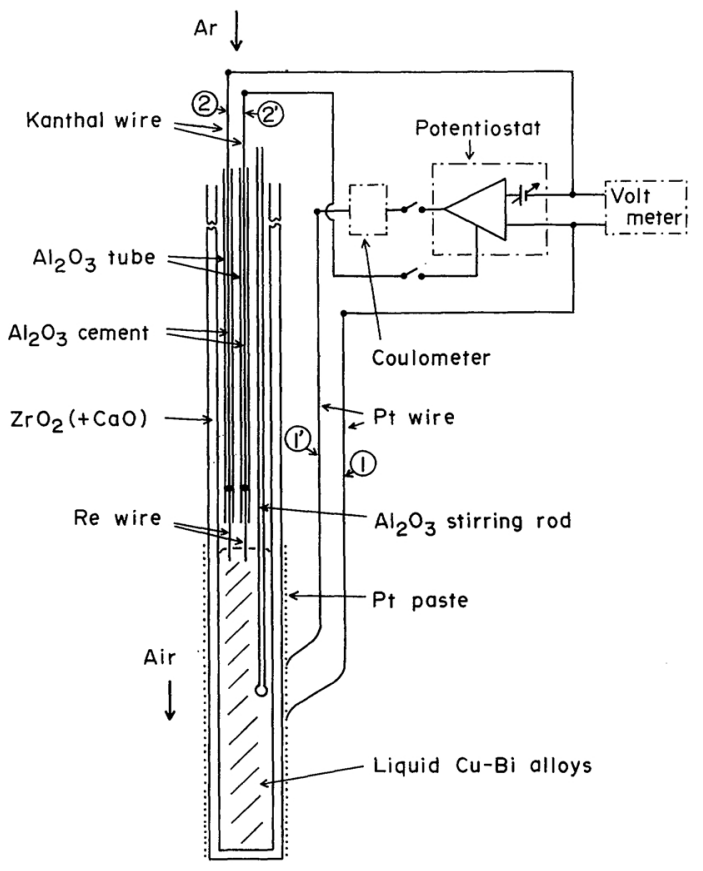

Fig. 1 Schematic diagram of the cell assembly. the initial open-circuit emf, $E_{1}(r)$, between wires (1) and (2) was approximately controlled to a preselected value corresponding to the relatively high oxygen concentration in the liquid alloy, by passing a current through the cell. After the current was switched off, the melt was stirred by moving an alumina rod up and down, and then the emf was monitored for $0.6 \mathrm{ks}$ or more without stirring the melt. The liquid alloy was stirred again, the alumina stirring rod was then pulled out of the melt, the initial emf $E_{1}(r)$ was recorded, and a potentiostatic pump-out experiment started by applying a voltage between wires (1) ${ }^{\prime}$ and (2) so that the emf between wires (1) and (2) was set at a preselected value of $E_{2}(\mathrm{~m})$. Such experiments were repeated under the condition of $\Delta E=E_{2}(m)-E_{1}(r)=200 \mathrm{mV}$. In the range of very low oxygen concentrations in liquid alloys, the open-circuit emf decreases with time because of electronic short-circuiting and the resultant oxygen transfer through the electrolyte from the reference electrode to the melt $^{(7)(9)}$. Therefore, a uniform initial oxygen concentration throughout the melt is established by applying a voltage between wires (1) ${ }^{\prime}$ and (2) ${ }^{\prime}$ for $1.8 \mathrm{ks}$ or more so that the emf between wires (1) and (2) has a preselected value of $E_{1}(m)$.

After starting the pump-out experiment, the electric current smoothly decreases with time and reaches a nearly constant value, $I_{\infty}$. Since this constant current is contributed by the electronic component, the ionic current, $I_{\text {ion }}$, passing through the cell can be evaluated by subtracting the constant value, $I_{\infty}$, from the total current. The apparent initial oxygen concentration, $C_{1}$ (app.) in $\mathrm{mol} \%$ for $E_{1}(r)$ or $E_{1}(m)$, is calculated from the quantity of electrical charge due to $I_{\text {ion }}$, according to ${ }^{(5)(9)}$

$$
\begin{aligned}
& C_{1} \text { (app.) } \\
& \quad=100 y\left\{(y+1)+(y-1) \exp \left(\frac{-2 \Delta E F}{R T}\right)\right\}^{-1},
\end{aligned}
$$

where $y=\left(Q_{\text {ion }} / 2 F\right) \times\left\{\left(W_{\mathrm{A}} / M_{\mathrm{A}}\right)+\left(W_{\mathrm{B}} / M_{\mathrm{B}}\right)\right\}^{-1}$, $Q_{\text {ion }}(\mathrm{C})$ is the quantity of electrical charge due to $I_{\text {ion }}, F$ the Faraday constant $(96484.56 \mathrm{C}$. $\left.\mathrm{mol}^{-1}\right), R$ the gas constant $\left(8.31441 \mathrm{~J} \cdot \mathrm{mol}^{-1}\right.$. $\mathrm{K}^{-1}$ ), $T$ the experimental temperature in $\mathrm{K}$, $\Delta E$ the difference between the initial and final 
emf, and $M_{\mathrm{A}}, W_{\mathrm{A}}, M_{\mathrm{B}}$ and $W_{\mathrm{B}}$ the molar mass and the mass of liquid solvent metals $\mathrm{A}$ and $\mathrm{B}$, respectively.

The true initial oxygen concentration in liquid alloys, $C_{1}$ (true), for relatively low values of $E_{1}(r)$ is evaluated from the $C_{1}$ (app.) values, according to the analytical procedure shown in previous papers ${ }^{(7)-(9)}$. The activity of oxygen in liquid alloys $a_{\underline{\mathrm{o}}}$, with respect to the standard state of oxygen gas at one atmospheric pressure is related to the true initial oxygen concentration and the initial emf, $E_{1}(r)$, by ${ }^{(5)(12)(13)}$

$$
\begin{aligned}
a_{\underline{\mathrm{O}}} & =\left(P_{\underline{\underline{\mathrm{O}}} 2} / P_{\mathrm{O}_{2}}^{*}\right)^{1 / 2}=\gamma_{\underline{\mathrm{Q}}} N_{1} \text { (true) }=\gamma_{\underline{\underline{Q}}} C_{1}(\text { true }) / 100 \\
& =\sqrt{0.21} \exp \left(\frac{-2 E_{1}(r) F}{R T}\right)
\end{aligned}
$$

where $P_{\mathrm{O}_{2}}$ is the initial equilibrium oxygen partial pressure over the liquid alloy in $\mathrm{Pa}$, $P_{\mathrm{O}_{2}}^{*}=101325 \mathrm{~Pa}, \gamma_{\underline{\mathrm{O}}}$ the activity coefficient of oxygen in the liquid alloy, and $N_{1}$ (true) the true initial oxygen concentration in the liquid alloy in mole fraction. The activity coefficient of oxygen, $\gamma_{\underline{0}}$, for each alloy composition can be calculated from the measured value of $C_{1}$ (true) for $E_{1}$ according to eq. (2).

\section{Experimental Results}

Immediately after a current was passed to control the initial oxygen concentration in the melt and switched off, the open-circuit emf, $E_{1}(r)$, increased at the rate of about 0.2 $\mathrm{mV}$ per $0.3 \mathrm{ks}$. The emf became gradually stable in $0.9 \mathrm{ks}$ and then decreased very slightly with time because of the slight leakage of oxygen through the electrolyte from air. However, once the melt was stirred by moving an alumina rod up and down, the emf became very stable.

Typical decay curves of electric current with time are shown in Fig. 2 for various emf's. The ionic current was evaluated by subtracting the nearly constant electronic current at $1.2 \mathrm{ks}$ from the measured current at earlier times, and then the $C_{1}$ (app.) value for $E_{1}(r)$ or $E_{1}(m)$ was calculated according to eq. (1). The error due to oxygen released from the solid electrolyte was evaluated from the $C_{1}$ (app.) values for the relatively large values of $E_{1}(m)$, in order to determine the $C_{1}$ (true) values for relatively

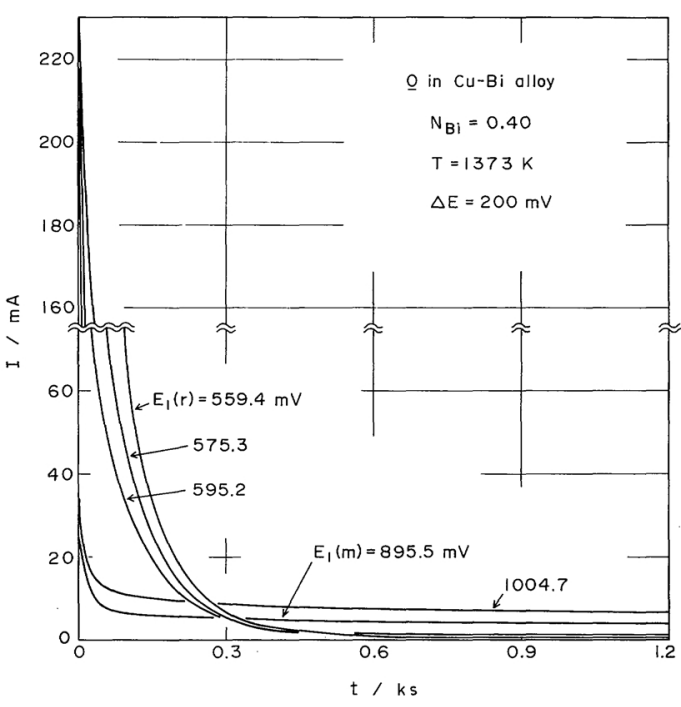

Fig. 2 Change in electric current with time for experiments with liquid $\mathrm{Cu}-\mathrm{Bi}$ alloy of $N_{\mathbf{B i}}=0.40$, at $1373 \mathrm{~K}$ and $\Delta E=200 \mathrm{mV}$.

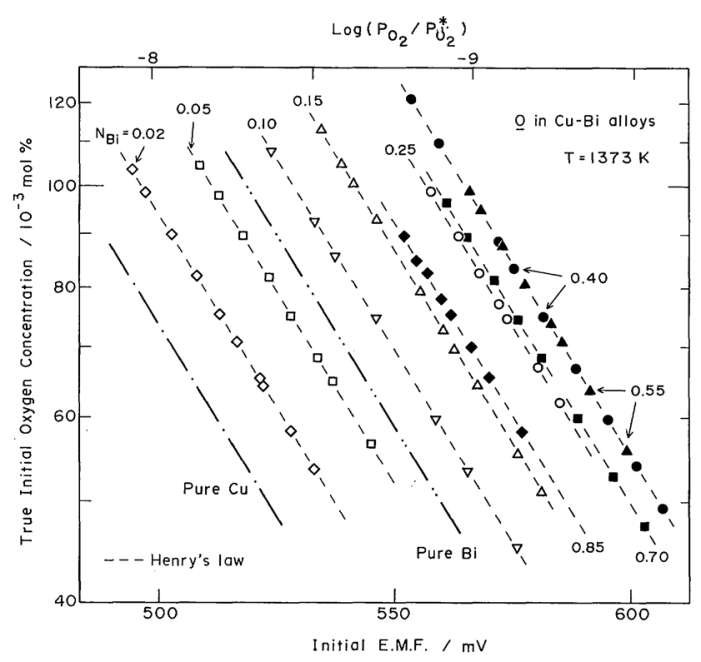

Fig. 3 True initial oxygen concentrations in various liquid $\mathrm{Cu}-\mathrm{Bi}$ alloys plotted against initial emf. $E_{1}(r)$, corresponding to the initial equilibrium oxygen partial pressure over those alloys.

low values of $E_{1}(r)$. Measured values of $C_{1}$ (true) are summarized in Table 1 with the corresponding values of $C_{1}$ (app.) and plotted in Fig. 3 as a function of the initial emf, $E_{1}(r)$. Figure 3 shows that the oxygen dissolved in liquid $\mathrm{Cu}-\mathrm{Bi}$ alloys obeys Henry's law indicated by each dashed line. It has been confirmed after each experiment that the weight loss of 
$\mathrm{Cu}-\mathrm{Bi}$ alloys due to the vaporization is less than 0.3 pct. Also, the rhenium wire was found to be a good lead wire for liquid $\mathrm{Cu}-\mathrm{Bi}$ alloys. In all respects, the present experiments were performed more successfully than previous ones with $\mathrm{Cu}-\mathrm{Tl}$ alloys ${ }^{(14)}$. This is in line with the previous observation that the results for Bi-based alloys were more reproducible than those for Tl-based alloys ${ }^{(5)(8)(10)}$.

The standard Gibbs energies of solution of oxygen in liquid $\mathrm{Cu}-\mathrm{Bi}$ alloys, $\Delta G^{\circ}$, for $1 / 2$ $\mathrm{O}_{2}(101325 \mathrm{~Pa}) \rightarrow \underline{\mathrm{O}}(1 \mathrm{~mol} \%)$ were calculated from these results, the reference state for dissolved oxygen being an infinitely dilute solution. The activity coefficients of oxygen, $\gamma_{\underline{0}}$, defined by eq. (2) were also calculated and the average value for each alloy composition is presented in Table 1 with the corresponding value of $\Delta G^{\circ}$. Very recently, two of the present authors have obtained the following equations for dissolutions of oxygen in pure $\mathrm{Cu}^{(9)}$ and $\mathrm{Bi}^{(10)}$ by the same modified coulometric titration method:

$\Delta G^{\circ}($ in $\mathrm{Cu}) / \mathrm{J} \cdot \mathrm{mol}^{-1}=-75500-0.12(\mathrm{~T} / \mathrm{K})$,

and

$\Delta G^{\circ}($ in $\mathrm{Bi}) / \mathrm{J} \cdot \mathrm{mol}^{-1}=-102310+14.29(\mathrm{~T} / \mathrm{K})$.

The values at $1373 \mathrm{~K}$ calculated from these equations are presented in Table 1 , together with the corresponding $\gamma_{\underline{0}}$ values. The chain lines for pure $\mathrm{Cu}$ and $\mathrm{Bi}$ in Fig. 3 is also based on these equations.

The logarithms of the experimental values of $\gamma_{\underline{0}}$ are plotted in Fig. 4 against the bismuth mole fraction, $N_{\mathrm{Bi}}$, and compared with those predicted by several models ${ }^{(2)-(5)(14)}$. As seen from Fig. 4, the experimental points exhibit considerable negative deviations from the additive equation. The present results were so reproducible that the scatter (within $\pm 80 \mathrm{~J}$ ) was covered by the data circles in Fig. 4. Besides, the systematic errors are less than $\pm 100 \mathrm{~J}$ in emf measurements and $\pm 200 \mathrm{~J}$ in the subtraction of the background of $C_{1}$ (app.).

\section{Discussion}

As shown in Fig. 4, the present experimental values exhibit large negative deviations from the additive equation over the whole composition range of alloys. Since the $\ln \gamma_{\underline{O}}$ value for $N_{\mathrm{Bi}} \leq 0.02$ appeared to vary linearly with $N_{\mathrm{Bi}}$, the interaction parameter of bismuth on oxygen, $\varepsilon_{0}^{(\mathbf{B i})}$, was calculated from the results for pure copper ${ }^{(9)}$ and $N_{\mathrm{Bi}}=0.02$ according to the relationship

$$
\varepsilon_{0}^{(\mathbf{B i})}=\left(\frac{\partial \ln \gamma_{\underline{Q}}}{\partial N_{\mathbf{B i}}}\right)_{N_{\mathbf{B i}} \rightarrow 0} .
$$

The evaluated value is $\varepsilon_{0}^{(\mathrm{Bi})}=-12.0$ at $1373 \mathrm{~K}$.

Recently, using an electrochemical cell, Taskinen and Hiltunen ${ }^{(15)}$ evaluated the oxygen concentration in liquid copper from emfdata, and then investigated the effect of the addition of bismuth on the emf up to $N_{\mathrm{Bi}}=$ 0.025 . Their value at $1373 \mathrm{~K}$ is $\varepsilon_{0}^{(\mathrm{Bi})}=-11.1$ and in excellent agreement with the present results. However, their data were restricted to the dilute alloys of bismuth because of some experimental problems. The advantage of the present modified coulometric titration method has been emphasized through a series of previous papers ${ }^{(8)(10)(16)(17)}$.

The present results are of much interest from a theoretical point of view, because $\gamma_{\underline{o}(\mathrm{Cu})}$ is nearly equal to $\gamma_{\underline{O}(\mathbf{B i})}$ and further the mixing enthalpy of $\mathrm{Cu}-\mathrm{Bi}$ alloys exhibits considerably large positive values. The experimental values of $\ln \gamma_{\mathrm{o}}$ at $1373 \mathrm{~K}$ are compared in Fig. 4 with those calculated from Jacob and Alcock's quasichemical equation $^{(2)}$ with $Z=8, n=4$, $\alpha=\frac{1}{2}$ :

$$
\frac{1}{\gamma_{\underline{Q}(\mathrm{~A}+\mathrm{B})}^{1 / \mathrm{n}}}=N_{\mathrm{A}} \frac{\gamma_{\mathrm{A}(\mathrm{A}+\mathrm{B})}^{\alpha}}{\gamma_{\underline{O}(\mathrm{~A})}^{1 / \mathrm{n}}}+N_{\mathrm{B}} \frac{\gamma_{\mathrm{B}(\mathrm{A}+\mathrm{B})}^{\alpha}}{\gamma_{\underline{Q}(\mathrm{~B})}^{1 / \mathrm{n}}},
$$

where $\gamma_{\underline{Q}(A+B)}, \gamma_{\underline{Q}(A)}$ and $\gamma_{\underline{Q}(B)}$ are the activity coefficients of the infinitely dilute solution of oxygen in A-B alloys, pure $A$ and $B$, respectively, $\gamma_{A(A+B)}$ and $\gamma_{B(A+B)}$, the activity coefficients of metals $\mathrm{A}$ and $\mathrm{B}$ in the A-B alloys, and $N_{\mathrm{A}}$ and $N_{\mathrm{B}}$, the mole fractions of the alloying elements $\mathrm{A}$ and $\mathrm{B}$. The binary data for $\mathrm{Cu}-\mathrm{Bi}$ alloys used in this calculation are taken from the compilation of Hultgren et $a ._{.}^{(6)}$, being available only for $N_{\mathrm{Bi}} \geq 0.22$.

As seen from Fig. 4, the trend of the compositional variation of the experimental $\ln \gamma_{0}$ values is similar to that of the values calculated from 
Table 1 Experimental values for various liquid $\mathrm{Cu}-\mathrm{Bi}$ alloys with previous results for $\mathrm{Cu}^{(9)}$ and $\mathrm{Bi}^{(10)}$.

\begin{tabular}{|c|c|c|c|c|c|c|c|c|}
\hline$N_{\mathrm{Bi}}$ & $\begin{array}{l}\text { Int. time } \\
W_{\mathbf{C u}}+W_{\mathbf{B i}}\end{array}$ & $E_{1}, \mathrm{mV}$ & $E_{2}, \mathrm{mV}$ & $\begin{array}{r}C_{1} \text { (app.) } \\
10^{-3} \mathrm{~mol} \%\end{array}$ & $\begin{array}{l}C_{1} \text { (true) } \\
10^{-3} \mathrm{~mol} \%\end{array}$ & $\mathrm{~kJ} \cdot \mathrm{mol}^{-1}$ & $\begin{array}{c}\text { Ave. } \\
-\Delta G^{\circ} \\
\mathrm{kJ} \cdot \mathrm{mol}^{-1}\end{array}$ & $\begin{array}{r}\text { Ave. } \\
-\ln \gamma_{0}\end{array}$ \\
\hline $0.00^{(9)}$ & & & & & & & 75.7 & 2.02 \\
\hline \multirow{12}{*}{0.02} & \multirow{12}{*}{$\begin{array}{l}(1.2 \mathrm{ks}) \\
10.125 \mathrm{~g}\end{array}$} & $494.4(r)$ & $694.6(m)$ & 105.2 & 103.5 & 78.42 & & \\
\hline & & $497.4(r)$ & $697.5(m)$ & 100.2 & 98.5 & 78.43 & & \\
\hline & & $502.9(r)$ & $703.2(m)$ & 91.65 & 90.0 & 78.46 & & \\
\hline & & $508.0(r)$ & $707.8(m)$ & 83.80 & 82.1 & 78.40 & & \\
\hline & & $512.9(r)$ & $713.3(\mathrm{~m})$ & 77.13 & 75.4 & 78.37 & & \\
\hline & & $516.7(r)$ & $716.3(\mathrm{~m})$ & 72.53 & 70.8 & 78.39 & & \\
\hline & & $521.7(r)$ & $721.7(m)$ & 67.27 & 65.5 & 78.46 & & \\
\hline & & $522.4(r)$ & $722.9(m)$ & 65.95 & 64.2 & 78.37 & & \\
\hline & & $528.2(r)$ & $728.3(m)$ & 60.10 & 58.3 & 78.39 & & \\
\hline & & $533.2(r)$ & $733.1(m)$ & 55.43 & 53.6 & 78.39 & 78.4 & 2.26 \\
\hline & & $895.2(m)$ & $1095.8(\mathrm{~m})$ & 6.02 & & & & \\
\hline & & $1005.2(\mathrm{~m})$ & $1205(m)$ & 8.59 & & & & \\
\hline \multirow{10}{*}{0.05} & \multirow{10}{*}{$\begin{array}{l}(1.2 \mathrm{ks}) \\
10.244 \mathrm{~g}\end{array}$} & $508.7(r)$ & $708.6(m)$ & 105.5 & 104.5 & 81.29 & & \\
\hline & & $512.8(r)$ & $712.6(m)$ & 98.64 & 97.6 & 81.30 & & \\
\hline & & $517.8(r)$ & $717.8(\mathrm{~m})$ & 90.56 & 89.5 & 81.28 & & \\
\hline & & $523.4(r)$ & $723.6(m)$ & 82.63 & 81.6 & 81.30 & & \\
\hline & & $528.0(r)$ & $728.3(m)$ & 76.29 & 75.2 & 81.26 & & \\
\hline & & $533.7(r)$ & $733.1(m)$ & 69.44 & 68.3 & 81.26 & & \\
\hline & & $536.8(r)$ & $736.8(m)$ & 66.05 & 64.9 & 81.27 & & \\
\hline & & $545.1(r)$ & $745.5(\mathrm{~m})$ & 57.62 & 56.5 & 81.29 & 81.3 & 2.51 \\
\hline & & $895.1(m)$ & $1095.6(m)$ & 5.82 & & & & \\
\hline & & $1005.6(\mathrm{~m})$ & $1206(\mathrm{~m})$ & 9.68 & & & & \\
\hline \multirow{9}{*}{0.10} & \multirow{9}{*}{$\begin{array}{c}(1.2 \mathrm{ks}) \\
9.758 \mathrm{~g}\end{array}$} & $523.9(r)$ & $723.3(m)$ & 109.0 & 107.8 & 84.58 & & \\
\hline & & $533.1(r)$ & $733.7(m)$ & 93.51 & 92.2 & 84.57 & & \\
\hline & & $537.4(r)$ & $737.3(m)$ & 86.65 & 85.3 & 84.51 & & \\
\hline & & $546.0(r)$ & $746.1(m)$ & 76.05 & 74.7 & 84.65 & & \\
\hline & & $558.8(r)$ & $758.9(m)$ & 61.13 & 59.7 & 84.56 & & \\
\hline & & $565.5(r)$ & $765.7(m)$ & 54.74 & 53.2 & 84.54 & & \\
\hline & & $575.8(r)$ & $776.2(m)$ & 46.72 & 45.1 & 84.64 & 84.6 & 2.80 \\
\hline & & $895.6(m)$ & $1095.1(m)$ & 7.17 & & & & \\
\hline & & $1005.3(\mathrm{~m})$ & $1205(m)$ & 12.02 & & & & \\
\hline \multirow{12}{*}{0.15} & \multirow{12}{*}{$\begin{array}{l}(1.2 \mathrm{ks}) \\
10.083 \mathrm{~g}\end{array}$} & $534.6(r)$ & $734.7(m)$ & 115.0 & 113.2 & 87.20 & & \\
\hline & & $539.0(r)$ & $739.2(m)$ & 106.5 & 104.6 & 87.15 & & \\
\hline & & $541.4(r)$ & $741.3(m)$ & 102.6 & 100.7 & 87.18 & & \\
\hline & & $546.2(r)$ & $746.0(m)$ & 94.66 & 92.8 & 87.17 & & \\
\hline & & $555.5(r)$ & $755.3(\mathrm{~m})$ & 81.24 & 79.3 & 87.17 & & \\
\hline & & $560.3(r)$ & $759.9(m)$ & 74.76 & 72.8 & 87.12 & & \\
\hline & & $562.7(r)$ & $762.7(m)$ & 71.84 & 69.8 & 87.10 & & \\
\hline & & $567.7(r)$ & $767.4(m)$ & 66.32 & 64.3 & 87.13 & & \\
\hline & & $576.3(r)$ & $775.9(\mathrm{~m})$ & 57.48 & 55.4 & 87.09 & & \\
\hline & & $581.2(r)$ & $780.7(\mathrm{~m})$ & 53.08 & 50.9 & 87.07 & 87.1 & 3.03 \\
\hline & & $895.6(m)$ & $1095.3(m)$ & 6.95 & & & & \\
\hline & & $1005.3(\mathrm{~m})$ & $1205(\mathrm{~m})$ & 10.45 & & & & \\
\hline \multirow{6}{*}{0.25} & \multirow{6}{*}{$\begin{array}{l}(1.2 \mathrm{ks}) \\
10.611 \mathrm{~g}\end{array}$} & $557.7(r)$ & $757.3(m)$ & 101.6 & 99.0 & 90.13 & & \\
\hline & & $563.4(r)$ & $763.8(\mathrm{~m})$ & 92.12 & 89.5 & 90.07 & & \\
\hline & & $568.1(r)$ & $767.9(\mathrm{~m})$ & 84.89 & 82.3 & 90.02 & & \\
\hline & & $572.1(r)$ & $772.0(m)$ & 79.64 & 77.0 & 90.04 & & \\
\hline & & $574.0(r)$ & $774.3(m)$ & 77.30 & 74.6 & 90.04 & & \\
\hline & & $580.3(r)$ & $779.9(\mathrm{~m})$ & 69.72 & 67.0 & 90.03 & & \\
\hline
\end{tabular}


Table 1 (continued)

\begin{tabular}{|c|c|c|c|c|c|c|c|c|}
\hline$N_{\mathrm{B} i}$ & $\begin{array}{l}\text { Int. time } \\
W_{\mathbf{C u}}+W_{\mathbf{B i}}\end{array}$ & $E_{1}, \mathrm{mV}$ & $E_{2}, \mathrm{mV}$ & $\begin{array}{r}C_{1} \text { (app.) } \\
10^{-3} \mathrm{~mol}^{\circ} \%\end{array}$ & $\begin{array}{l}C_{1} \text { (true) } \\
10^{-3} \mathrm{~mol} \%\end{array}$ & $\begin{array}{r}-\Delta G^{\circ} \\
\mathrm{kJ} \cdot \mathrm{mol}^{-1}\end{array}$ & $\begin{array}{c}\text { Ave. } \\
-\Delta G^{\circ} \\
\mathrm{kJ} \cdot \mathrm{mol}^{-1}\end{array}$ & $\begin{array}{r}\text { Ave. } \\
-\ln \gamma_{\underline{o}}\end{array}$ \\
\hline & & $585.0(r)$ & $784.5(m)$ & 64.73 & 62.0 & 90.05 & 90.1 & 3.28 \\
\hline & & $895.2(m)$ & $1095.6(\mathrm{~m})$ & 7.57 & & & & \\
\hline & & $1005.7(m)$ & $1205(m)$ & 10.81 & & & & \\
\hline \multirow{11}{*}{0.40} & \multirow{11}{*}{$\begin{array}{l}(1.2 \mathrm{ks}) \\
10.409 \mathrm{~g}\end{array}$} & $553.6(r)$ & $753.9(m)$ & 123.4 & 121.3 & 91.65 & & \\
\hline & & $559.4(r)$ & $759.8(m)$ & 112.0 & 109.8 & 91.64 & & \\
\hline & & $572.3(r)$ & $772.9(m)$ & 90.54 & 88.3 & 91.64 & & \\
\hline & & $575.3(r)$ & $775.8(m)$ & 85.72 & 83.4 & 91.57 & & \\
\hline & & $581.7(r)$ & $782.3(m)$ & 77.14 & 74.8 & 91.56 & & \\
\hline & & $588.5(r)$ & $788.9(m)$ & 69.20 & 66.8 & 91.58 & & \\
\hline & & $595.2(r)$ & $795.4(m)$ & 62.25 & 59.7 & 91.59 & & \\
\hline & & $601.3(r)$ & $801.1(m)$ & 56.50 & 53.9 & 91.60 & & \\
\hline & & $606.8(r)$ & $806.7(m)$ & 52.11 & 49.5 & 91.69 & 91.6 & 3.42 \\
\hline & & $895.5(m)$ & $1096.0(\mathrm{~m})$ & 8.47 & & & & \\
\hline & & $1004.7(\mathrm{~m})$ & $1205(m)$ & 13.17 & & & & \\
\hline \multirow{10}{*}{0.55} & \multirow{10}{*}{$\begin{array}{l}(1.2 \mathrm{ks}) \\
11.047 \mathrm{~g}\end{array}$} & $565.9(r)$ & $765.6(m)$ & 102.7 & 98.8 & 91.69 & & \\
\hline & & $568.3(r)$ & $768.3(m)$ & 98.60 & 94.7 & 91.67 & & \\
\hline & & $572.9(r)$ & $773.1(\mathrm{~m})$ & 91.63 & 87.6 & 91.66 & & \\
\hline & & $577.7(r)$ & $777.8(m)$ & 84.47 & 80.4 & 91.61 & & \\
\hline & & $583.3(r)$ & $783.4(m)$ & 77.72 & 73.6 & 91.68 & & \\
\hline & & $585.5(r)$ & $785.4(\mathrm{~m})$ & 74.81 & 70.7 & 91.65 & & \\
\hline & & $591.6(r)$ & $791.8(m)$ & 67.83 & 63.6 & 91.62 & & \\
\hline & & $599.2(r)$ & $798.6(m)$ & 60.07 & 55.7 & 91.57 & 91.6 & 3.42 \\
\hline & & $895.1(m)$ & $1095.4(\mathrm{~m})$ & 11.64 & & & & \\
\hline & & $1005.5(\mathrm{~m})$ & $1205(m)$ & 16.80 & & & & \\
\hline \multirow{10}{*}{0.70} & \multirow{10}{*}{$\begin{array}{l}(1.2 \mathrm{ks}) \\
11.816 \mathrm{~g}\end{array}$} & $561.1(r)$ & $761.1(m)$ & 99.82 & 96.3 & 90.47 & & \\
\hline & & $565.4(r)$ & $764.8(m)$ & 92.89 & 89.4 & 90.45 & & \\
\hline & & $571.0(r)$ & $771.2(m)$ & 84.75 & 81.2 & 90.43 & & \\
\hline & & $576.3(r)$ & $777.0(m)$ & 77.98 & 74.3 & 90.44 & & \\
\hline & & $581.2(r)$ & $780.7(m)$ & 71.89 & 68.2 & 90.41 & & \\
\hline & & $589.0(r)$ & $789.0(m)$ & 63.77 & 59.9 & 90.43 & & \\
\hline & & $596.4(r)$ & $796.7(m)$ & 56.56 & 52.6 & 90.38 & & \\
\hline & & $603.1(r)$ & $803.3(m)$ & 51.24 & 47.2 & 90.43 & 90.4 & 3.32 \\
\hline & & $895.3(m)$ & $1095.0(\mathrm{~m})$ & 11.56 & & & & \\
\hline & & $1005.7(m)$ & $1206(\mathrm{~m})$ & 17.19 & & & & \\
\hline \multirow{10}{*}{0.85} & \multirow{10}{*}{$\begin{array}{l}(1.2 \mathrm{ks}) \\
11.146 \mathrm{~g}\end{array}$} & $551.9(r)$ & $751.5(m)$ & 94.69 & 89.5 & 87.86 & & \\
\hline & & $554.6(r)$ & $754.3(\mathrm{~m})$ & 90.10 & 84.8 & 87.76 & & \\
\hline & & $557.1(r)$ & $757.1(m)$ & 87.75 & 82.4 & 87.92 & & \\
\hline & & $560.0(r)$ & $760.0(m)$ & 83.34 & 78.0 & 87.85 & & \\
\hline & & $561.9(r)$ & $761.9(m)$ & 80.82 & 75.4 & 87.83 & & \\
\hline & & $566.3(r)$ & $766.7(m)$ & 75.50 & 70.0 & 87.83 & & \\
\hline & & $570.1(r)$ & $770.3(m)$ & 70.92 & 65.4 & 87.79 & & \\
\hline & & $577.1(r)$ & $777.0(m)$ & 63.65 & 58.0 & 87.77 & 87.8 & 3.09 \\
\hline & & $895.0(m)$ & $1095.4(m)$ & 15.31 & & & & \\
\hline & & $1005.4(m)$ & $1205(m)$ & 21.62 & & & & \\
\hline $1.00^{(10)}$ & & & & & & & 82.7 & 2.64 \\
\hline
\end{tabular}

* $\quad(r)$ and $(m)$ indicate $E(r)$ and $E(m)$, respectively. 


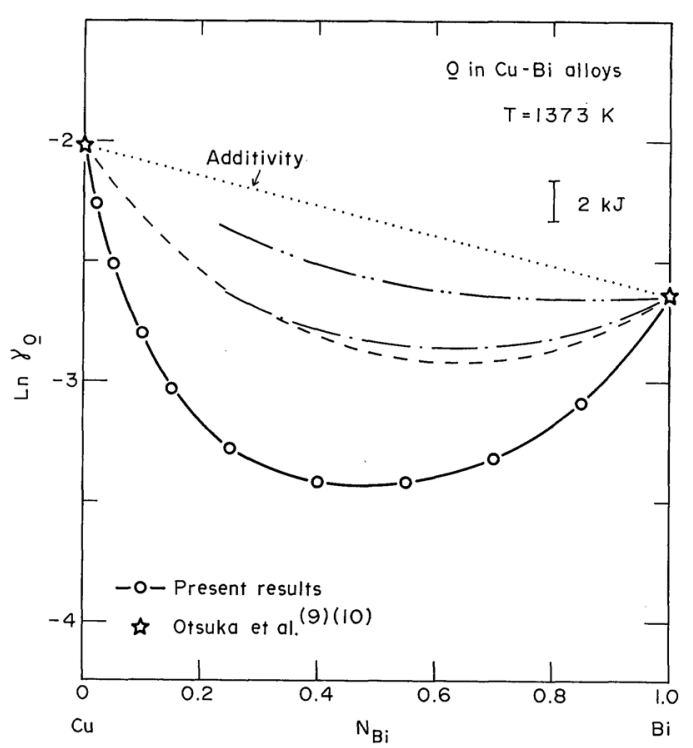

Fig. 4 Variations of $\ln \gamma_{0}$ with mole fraction of bismuth in $\mathrm{Cu}-\mathrm{Bi}$ alloys at $1373 \mathrm{~K}$. O年; experimental values of the authors, - - - ; from Jacob and Alcock's ${ }^{(2)}$ eq. (6), $\left(Z=6, n=4, \alpha=\frac{1}{2}\right),-\cdots$ - ; from Wagner's equation $^{(3)}$ on the basis of relationship (7), - - ; from eq. (8) ${ }^{(14)}$ according to regular solution model.

eq. (6). However, the magnitudes differ considerably. Similar negative deviations of the measured values from the calculated ones were also observed for Bi-Tl-O system ${ }^{(5)}$. Recently, Blander et $a l .{ }^{(18)}$ discussed on the Jacob and Alcock's eq. (6) and pointed out the possibility that (at least for the case of alloys) the "decrease in the metallic bonding" near a solute atom may be accompanied by an increase of some other type of bonding (e.g., bonds having some ionic character for electronegative solutes). Two of the present authors ${ }^{(5)(12)}$ have pointed out another possibility that the average composition of the metal forming bonds with metal atoms bonded to oxygen may deviate from the bulk's one so that the energy of the system can be lowered. Negative deviations of the experimental points from quasichemical model (6) can be explained by these considerations.

A dotted line in Fig. 4 shows calculated values according to the theoretical equation of Wagner ${ }^{(3)}$. One adjustable energy parameter, $h$, involved in his equation has been predicted by the following relationship:

$$
\begin{aligned}
h= & \frac{2 \varepsilon}{Z^{2}}+0.09\left\{\varepsilon\left(\frac{V_{\mathrm{a}}}{V_{\mathrm{b}}}\right)^{2}\right\} \\
& +0.04\left|\Delta G^{\circ}(\mathrm{A})-\Delta G^{\circ}(\mathrm{B})\right|,
\end{aligned}
$$

which was first proposed by Chang et al. ${ }^{(4)(19)}$ and then improved by two of the present authors (S.O. and Z.K.) ${ }^{(5)(12)} . V_{\mathrm{a}}$ and $V_{\mathrm{b}}$ are the metallic valences of the alloying elements $A$ and $B$ which are always selected to make $\left(V_{\mathrm{b}} / V_{\mathrm{a}}\right) \leq 1 . \Delta G^{\circ}(\mathrm{A})$ and $\Delta G^{\circ}(\mathrm{B})$ are the standard Gibbs energy of solution of oxygen for solvent metals $\mathrm{A}$ and $\mathrm{B}$, respectively, and $Z$ is the coordination number of the dissolved oxygen $(Z=6)$. In this calculation, the values of 5.56 and 1.56 were used as the metallic valences of $\mathrm{Cu}$ and $\mathrm{Bi}$, which were taken from Pauling ${ }^{(20)}$. The regular solution parameter, $\varepsilon$, was evaluated by using the equation, $\varepsilon=$ $\Delta H_{\max \text { or min }} /(0.5 \times 0.5)$, where $\Delta H_{\text {max or min }}$ is the maximum or minimum values of the mixing enthalpy $\Delta H$ for the A-B alloys. This equation has been recommended in previous papers $^{(5)(12)(21)}$. The $\Delta H$ value of $1200 \mathrm{~K}$ compiled by Hultgren et al. ${ }^{(6)}$ was used in this calculation. It is assumed that $\Delta H$ is constant over the temperature range considered. The evaluated values of $\varepsilon$ and $h$ are $+21670 \mathrm{~J} \cdot \mathrm{mol}^{-1}$ and $+1640 \mathrm{~J} \cdot \mathrm{mol}^{-1}$, respectively. As seen from Fig. 4, the $\gamma_{\mathrm{o}}$ values calculated from the Wagner one-parameter equation by this procedure are almost equivalent with the value based on the quasichemical eq. (6).

Recently, it was pointed out (22) that the regular solution model successfully described the compositional variation of $\gamma_{\underline{o}}$ in liquid Bi-Tl alloys ${ }^{(5)}$. The corresponding equation proposed by Alcock and Richardson ${ }^{(14)}$ is

$$
\ln \gamma_{\underline{\mathrm{O}}(\mathrm{A}+\mathrm{B})}=N_{\mathrm{A}} \ln \gamma_{\underline{\mathrm{O}}(\mathrm{A})}+N_{\mathrm{B}} \ln \gamma_{\underline{\mathrm{O}}(\mathrm{B})}-G^{\mathrm{E}} / R T,
$$

where $G^{\mathrm{E}}$ is the molar excess Gibbs energy of mixing for the solvent alloys.

The value for the $\mathrm{Cu}-\mathrm{Bi}-\mathrm{O}$ system, calculated from eq. (8), is indicated by a dash-dot-dot line in Fig. 4. Since the strength of $\mathrm{Bi}-\mathrm{O}$ bond is likely similar to that of $\mathrm{Cu}-\mathrm{O}$ bond, the average composition of metal bonded to oxygen must be nearly equal to the bulk composition. Therefore, eq. (8) may be expected to work for the 
$\mathrm{Cu}-\mathrm{Bi}-\mathrm{O}$ system. However, as shown in Fig. 4, the value calculated from eq. (8) differed significantly from the experimental points, and is rather close to the additive equation, $N_{\mathrm{A}} \ln$ $\gamma_{\underline{O}(\mathrm{~A})}+N_{\mathrm{B}} \ln \gamma_{\underline{Q}(\mathrm{~B})}$. This arises from the fact that the calculated $\gamma_{\underline{Q}}$ values from eq. (8) are not sensitive enough to change the $G^{\mathrm{E}}$ value. Since a strong metal-oxygen bonding leads to an increase of more stable bonding near the oxygen, as described above ${ }^{(5)(12)(18)}$, the regular solution model (8) appears not to be suitable even for systems satisfying the condition of $\gamma_{\underline{Q}(\mathrm{~A})} \approx \gamma_{\underline{\mathrm{O}}(\mathrm{B})}$.

A more generalized theoretical equation that by Jacob and Alcock or by Wagner has been proposed by Blander et al. ${ }^{(18)}$. In view of more parameters of $Z, t$ and $h$ included in their equation, attempt will be made to find out some correlations between those parameters when experimental data for more various systems become available.

\section{REFERENCES}

(1) C. B. Alcock and F. D. Richardson: Acta Met., 8 (1960), 882.

(2) K. T. Jacob and C. B. Alcock: Acta Met., 20 (1972), 221.

(3) C. Wagner: Acta Met., 21 (1973), 1297.

(4) T. Chiang and Y. A. Chang: Met. Trans. B, 7B (1976), 453.

(5) S. Otsuka, T. Sano and Z. Kozuka: Trans. JIM, 22 (1981), 35.
(6) R. Hultgren, P. D. Desai, D. T. Hawkins, M. Gleiser and K. K. Kelley: Selected Values of the Thermodynamic Properties of Binary Alloys, ASM, Metals Park, Ohio, (1973).

(7) S. Otsuka and Z. Kozuka: Met. Trans. B, 10B (1979), 565.

(8) S. Otsuka, T. Sano and Z. Kozuka: Met. Trans. B, $11 B$ (1980), 313.

(9) S. Otsuka and Z. Kozuka: Met. Trans. B, 12B (1981), 501.

(10) S. Otsuka, T. Sano and Z. Kozuka: Met. Trans. B, $12 B$ (1981), 427.

(11) S. Otsuka, Y. Matsumura and Z. Kozuka: Solid State Ion., 3/4 (1981), 495.

(12) S. Otsuka and Z. Kozuka: Met. Trans. B, 12B (1981), 455.

(13) K. Kiukkola and C. Wagner: J. Electrochem. Soc., 104 (1957), 379.

(14) C. B. Alcock and F. D. Richardson: Acta Met., 6 (1958), 385.

(15) P. Taskinen and H. Hiltunen: Scand. J. Metall., 8 (1979), 39.

(16) S. Otsuka, Y. Matsumura and Z. Kozuka: Met. Trans. B, 13B (1982), 77.

(17) S. Otsuka and Z. Kozuka: Met. Trans. B, 12B (1981), 616.

(18) M. Blander, M-L. Saboungi and P. Cerisier: Met. Trans. B, 10B (1979), 613.

(19) R. Y. Lin and Y. A. Chang: Met. Trans. B, 8B (1977), 293.

(20) L. Pauling: The Chemical Bond, Cornell Univ., (1967).

(21) S. Otsuka, H. Hanaoka and Z. Kozuka: Trans. JIM, 23 (1982), 70.

(22) Y. A. Chang: private communication, Univ. of Wisconsin-Madison, U.S.A., April 1981. 